\title{
Production of Methanol from Heat-stressed Pepper and Corn Leaf Disks
}

\author{
Jeffrey A. Anderson \\ Department of Horticulture and Landscape Architecture, Oklahoma State University, Stillwater, \\ OK 74078-0511
}

Additional index words. Capsicum annuum, Zea mays, acetaldehyde, ethane, ethanol, ethylene, electrolyte leakage, peroxidation, linoleic acid, linolenic acid, fatty acid

\begin{abstract}
Early Calwonder' pepper (Capsicum annuum L.) and 'Jubilee' corn (Zea mays L.) leaf disks exposed to high temperature stress produced ethylene, ethane, methanol, acetaldehyde, and ethanol based on comparison of retention times during gas chromatography to authentic standards. Methanol, ethanol, and acetaldehyde were also identified by mass spectroscopy. Corn leaf disks produced lower levels of ethylene, ethane, and methanol, but more acetaldehyde and ethanol than pepper. Production of ethane, a by-product of lipid peroxidation, coincided with an increase in electrolyte leakage (EL) in pepper but not in corn. Compared with controls, pepper leaf disks infiltrated with linolenic acid evolved significantly greater amounts of ethane, acetaldehyde, and methanol and similar levels of ethanol. EL and volatile hydrocarbon production were not affected by fatty acid infiltration in corn. Infiltration of pepper leaves with buffers increasing in pH from 5.5 to 9.5 increased methanol production.
\end{abstract}

Plant tissues produce volatile hydrocarbons, with emission frequently increasing after exposure to environmental stress. A broad range of plant taxa produce methanol (MacDonald and Fall, 1992; Robinson, 1991). Methanol was released from isolated plant cell walls after base hydrolysis of galacturonic methyl esters (McFeeters and Armstrong, 1984). A reduction in methylation of galacturonic acid residues in cell walls of chilled cucumbers (Cucumis sativus L.) may have been related to pectin methylesterase (EC 3.1.1.11) activity (Fukushima, 1978).

Ethanol and acetaldehyde emission from apple (Malus domestica Borkh.) roots was stimulated by elevated temperatures (Gur et al., 1972). Accelerated aging of soybean (Glycine max L.) seeds at $41 \mathrm{C}$ and $100 \%$ relative humidity for 5 days resulted in a stimulation of acetaldehyde and ethanol production after imbibition, an effect attributed to an imbalance between the tricarboxylic acid and glycolytic pathways (Woodstock and Taylorson, 1981). Kimmerer and Kozlowski (1982) reported ethanol, acetaldehyde, ethylene, and ethane production from leaves fumigated with $\mathrm{SO}_{2}$. Ethylene and ethane were also generated in response to freezing (Elstner and Konze, 1976; Harber and Fuchigami, 1986), chilling (Wise and Naylor, 1987), and heat stress (Nanaiah and Anderson, 1992). Ethylene is produced from 1-aminocyclopropane carboxylic acid (ACC) in the methionine pathway (Adams and Yang, 1979), whereas ethane is derived from oxidation of polyunsaturated fatty acids (John and Curtis, 1977).

During preliminary studies on biotic and abiotic stresses, a peak was observed during gas chromatography that was consistent with the retention time of methanol. The primary objectives of this study were to verify the identity of the compound and to determine the effects of heat stress on its production in pepper and corn leaf

Received for publication 19 Apr. 1993. Accepted for publication 9 Aug. 1993. Approved for publication by the director of the Oklahoma Agricultural Experiment Station. This research was supported under project H-2002 and the Targeted Research Initiative Program of the Oklahoma Agricultural Experiment Station. I gratefully acknowledge the technical assistance of Glenn Drown, Craig McKenzie, and Thayne Vickstrom. Mention of a trademark, proprietary product, or vendor does not constitute a guarantee or warranty of the product and does not imply its approval to the exclusion of other products or vendors that may also be suitable. The cost of publishing this paper was defrayed in part by the payment of page charges. Under postal regulations, this paper therefore must be hereby marked advertisement solely to indicate this fact. disks. Pepper leaves were infiltrated with buffer solutions with pHs from 5.5 to 9.5 to determine the likelihood of methanol being derived from base hydrolysis of pectin methyl esters. A secondary objective was to determine whether the divergent patterns in ethane evolution from pepper and corn leaves was the result of substrate availability.

\section{Materials and Methods}

Heat stress. Pepper and corn seedlings were grown in 36-liter pots in a growth chamber as previously described (Anderson et al., 1990), except 24 day/20C night cycles were maintained with a 14-h photoperiod. The fifth through seventh leaves, numbered basipetally, from 41- to 49-day-old corn plants and fully expanded leaves from 60- to 80-day-old pepper plants were sampled between 8:30 and 9:30 AM. Disks were cut with a 9-mm-diameter cork borer, avoiding the midrib in corn and the midrib and largest lateral veins in pepper. High-temperature exposure was conducted as previously described (Nanaiah and Anderson, 1992), with 10 leaf disks sealed in a $16.7-\mathrm{ml}$ vial with a Teflon-lined septum for head-space analysis and three additional disks placed in a $25 \times 150$-mm test tube with $20 \mathrm{ml}$ distilled water for electrolyte leakage (EL) measurements. Head-space samples were collected after $22 \mathrm{~h}$ of incubation and EL was measured after $24 \mathrm{~h}$ at $24 \mathrm{C}$ as previously described (Anderson et al., 1990).

Fatty acid infiltration. Fatty acid (cis-9,12 linoleic or cis-9,12,15 linolenic acid) emulsions were prepared by adding 155 or $152 \mu 1$, respectively, of the free acid (Sigma Chemical Co., St. Louis) to a solution of $1 \mathrm{ml}$ distilled water and $10 \mu \mathrm{l}$ Tween 20 (polyoxyethylene-sorbitan). The mixture was sonicated and periodically swirled while slowly being diluted with distilled water. Final concentrations of fatty acids and Tween 20 were $5 \mathrm{~mm}$ and $0.01 \%$ (by volume), respectively. Pepper and corn leaf disks were held under vacuum in treatment emulsions for $5 \mathrm{~min}$, then slowly equilibrated to atmospheric pressure. Leaf disks were blotted dry, then 10 disks were placed in each vial for head-space analysis and three additional disks were placed in each test tube for EL measurements. Head-space samples were collected and EL was measured after $3 \mathrm{~h}$ at $24 \mathrm{C}$.

Buffer infiltration. Pepper leaves were syringe-infiltrated with distilled water, 2-[N-morpholino] ethanesulfonic acid (MES) buffer 
adjusted to a $\mathrm{pH}$ of 5.5 , or bis-tris propane (BTP) at $\mathrm{pH} 6.5,7.5,8.5$, or 9.5. Ten leaf disks for each of three subsamples for each treatment were punched with a cork borer and sealed in vials as described above. Disks remained watersoaked during the $24 \mathrm{~h}$ of incubation at $24 \mathrm{C}$ in the dark before head-space analysis. A similar series of experiments was conducted to determine the solute and ion effects on methanol production. Leaves were syringe-infiltrated with BTP $(\mathrm{pH}=9.5), \mathrm{NaCl}$, or mannitol at 1,50 , or $100 \mathrm{~mm}$ or distilled water, then treated as described in buffer experiments. Data were expressed on a dry-weight basis since tissues were infiltrated before excision.

Gas chromatography. A gas-tight syringe with a Teflon plunger was used to inject $1 \mathrm{ml}$ head-space gas into a gas chromatograph (GC) (model 540; Tracor Instruments, Austin, Texas). The GC was equipped with a $30-\mathrm{m} \times 0.53-\mathrm{mm}$ column (GS-Q Megabore; J \& W Scientific, Folsom, Calif.) and flame ionization detector. Helium carrier gas flowed at $93 \mathrm{~cm} \cdot \mathrm{s}^{-1}$. The oven was programmed for $2 \mathrm{~min}$ at $60 \mathrm{C}$, then increased at $10 \mathrm{C} / \mathrm{min}$ to $140 \mathrm{C}$ and held there for $2 \mathrm{~min}$. Injector and detector temperatures were 180 and 200C, respectively. Mean production rates were calculated from response factors derived from standards. Gaseous standards were purchased from Scott Specialty Gases (Plumsteadville, Pa.). Acetaldehyde, ethanol, and methanol standards were prepared from the liquid phase transferred to a 2-liter static dilution bottle (Tekmar, Cincinnati). Acetaldehyde was transferred in a chilled microliter syringe to prevent premature volatilization.

GC-mass spectrometry (MS) was conducted with a GC (HP 5890; Hewlett Packard, Palo Alto, Calif.), using the same GS-Q column used for GC measurements, interfaced with a MS (TS-250; VG Analytical, Manchester, England). The oven was programmed to maintain $40 \mathrm{C}$ for $3 \mathrm{~min}$, then increased $5 \mathrm{C} / \mathrm{min}$ to $140 \mathrm{C}$ and held there for $20 \mathrm{~min}$. The data were acquired using $70 \mathrm{eV}$ electron impact ionization in positive mode, scanning the mass-to-charge ratio from 10 to 150 at $2-\mathrm{sec}$ intervals. Fifty pepper leaf disks per vial were held at $55 \mathrm{C}$ for $15 \mathrm{~min}$, then incubated for $22 \mathrm{~h}$ at $24 \mathrm{C}$ before injection of $2.5 \mathrm{ml}$ head-space gas. Mass spectra from authentic standards and tissue samples were determined on two dates with similar results.

All experiments contained at least three subsamples per treatment combination and were conducted on at least three dates. Mean separations by Duncan's multiple range test were conducted as appropriate after analysis of variance. Trend analysis was used in experiments with concentration series, specifying L-vector parameters using coefficients for unequally spaced treatments (Little and Hills, 1978).

\section{Results and Discussion}

Heat stress. Ethylene, ethane, ethanol, acetaldehyde, and methanol were detected by GC of head-space samples from pepper and corn leaf disks after heat stress. Another unidentified peak at $\approx 9.15$ min was frequently observed in pepper and corn, but quantities were highly variable from sample to sample and showed no correlation to treatments. Positive identification of acetaldehyde, methanol, and ethanol was provided by mass spectra. For example, methanol was identified based on peaks, in decreasing intensity, at $\mathrm{m} / \mathrm{z}=31,29,32$, and 15 . Ethylene and ethane eluted too close to the air peak for accurate determination, and positive identification of the compound eluting at $9.15 \mathrm{~min}$ was not made. Acetone produced a peak at this retention time, a result indicating that this compound could not be ruled out as producing the 9.15 peak.

The pattern of methanol production matched EL closely in pepper, but methanol increased at a lower temperature than EL in corn (Fig. 1). Most stress gases exhibited a peak in production at or near the temperatures corresponding to a transition from uninjured to killed cells, based on EL. Decreasing amounts of stress gases, other than methanol, at temperatures greater than the peak temperature may reflect thermal instability of enzymes involved in their production. Previous reports of ethane production after freezing (Chalker-Scott et al., 1989) and heat stress (Nanaiah and Anderson, 1992) have indicated peaks at or near the killing temperature and decreasing levels with increasing stress intensity. Ethylene peaked at $45 \mathrm{C}$ in pepper, before a large increase in EL, and ethane peaked at the lowest treatment temperature that produced maximal EL. Ethylene and ethane production from corn was less than from pepper and exhibited little or no relationship to treatment temperature or EL other than a lack of ethylene production at temperatures $>45 \mathrm{C}$. Ethane production was consistent with lipid peroxidative damage in pepper but not in corn. A peak in ethane production in corn treated at $65 \mathrm{C}$ may represent a secondary response not directly related to the primary events during injury.

The most ethanol and acetaldehyde was observed at 50 and $55 \mathrm{C}$, respectively, in corn and at 55C in pepper. Corn leaf disks produced more acetaldehyde and ethanol than pepper, but less methanol. Relative amounts of acetaldehyde and ethanol detected by head-space sampling do not necessarily reflect tissue levels. Although neither compound accumulated appreciably in stressed tissues incubated at 25C (Kimmerer and Kozlowski, 1982), acetaldehyde and ethanol have different boiling points (21 and 78.5C, respectively) and gas-liquid partition coefficients (Kimmerer and MacDonald, 1987). Although O levels were not measured in vials used for head-space sampling, it is possible that hypoxic conditions interacted with heat stress to stimulate production of hydrocarbons such as ethanol and acetaldehyde.

Smagula and Bramlage (1977) reviewed the literature dealing with acetaldehyde in fruit and reported accumulation in tissues with various disorders that may contribute to symptom development or loss of cell viability. However, cause and effect relationships between the accumulation of stress-induced compounds and cellular injury have not been established. Kimmerer and Kozlowski (1982) reported that leaves did not consistently produce acetaldehyde and ethanol when exposed to a variety of stresses. Similarly, they observed ethanol and acetaldehyde evolution from some species, but not others, after freezing stress. The evolution of glycolytic products from stressed tissues may be a symptom of injury and not a cause, since tissues have been reported to tolerate relatively high concentrations of ethanol (Saltveit and Ballinger, 1983). However, acetaldehyde toxicity has been observed in carrot cell cultures (Perata and Alpi, 1991).

Fatty acid infiltration. Pepper leaf responses to fatty acid infiltration were a function of the number of double bonds, as previously reported (Nanaiah and Anderson, 1992). Linolenic acid caused greater EL than controls, and values for linoleic acid were intermediate (Table 1). Production of ethane, acetaldehyde, and methanol from disks infiltrated with linolenic acid was significantly higher than from linoleic acid and controls. No significant differences in ethylene, ethanol, or pentane levels were observed. Pentane, an in vitro oxidation product of linoleic acid (Dumelin and Tappel, 1977), was detected in variable levels after infiltration with linoleic acid. Pentane was rarely detected and only in trace amounts from heat-stressed tissues (data not presented). EL and volatile hydrocarbon production from corn leaves was not affected by fatty acid infiltration (data not presented). Apparently, the availability of free (nonesterified) fatty acids did not limit ethane production in corn.

Although treatments were not from the same series of experi- 


\section{PEPPER}

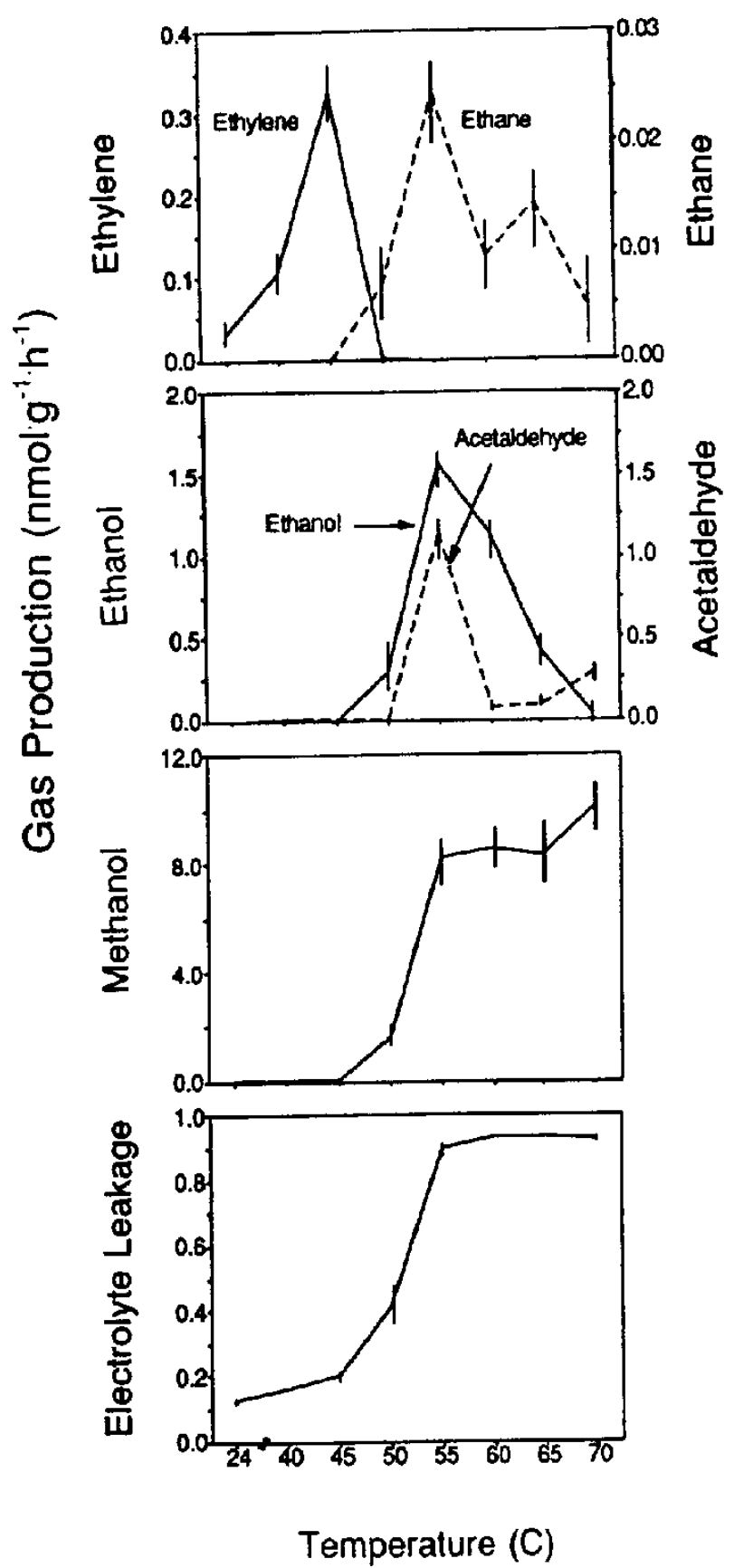

CORN
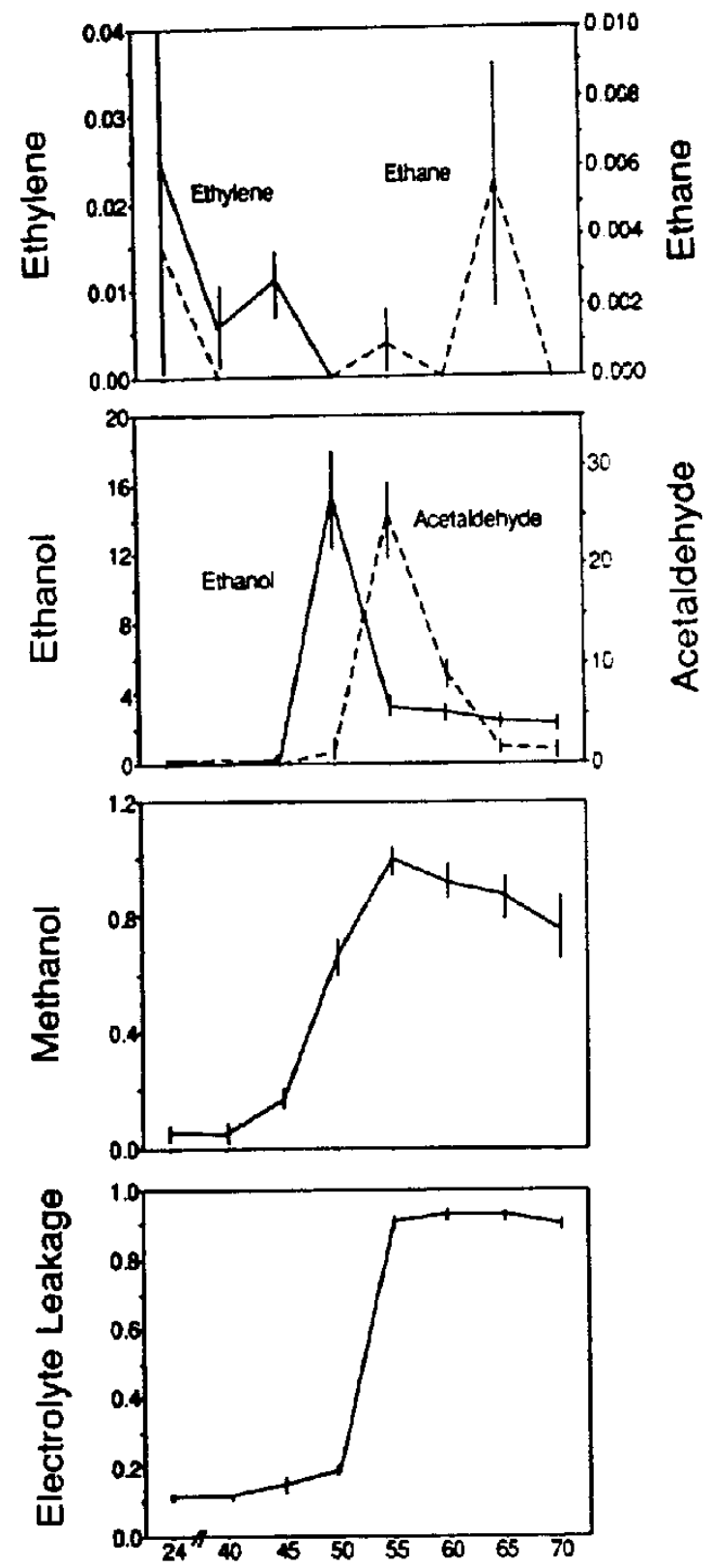

Temperature (C)

Fig. 1. Electrolyte leakage and production of ethylene, ethane, ethanol, acetaldehyde, and methanol from pepper and corn leaf disks after high-temperature stress. Values are means \pm SE of nine measurements.

Table 1. Electrolyte leakage and stress gas production from pepper leaf disks measured $3 \mathrm{~h}$ after infiltration with fatty acids or distilled water. All treatments contained $0.01 \%$ (by volume) Tween 20 . Values are means of nine measurements.

\begin{tabular}{|c|c|c|c|c|c|c|c|}
\hline \multirow[b]{2}{*}{ Treatment } & \multirow{2}{*}{$\begin{array}{c}\text { Electrolyte } \\
\text { leakage }\end{array}$} & \multicolumn{6}{|c|}{ Stress gas production (nmol/g fresh wt per $\mathrm{h}$ ) } \\
\hline & & Ethylene & Ethane & Acetaldehyde & Methanol & Ethanol & Pentane \\
\hline Control & $0.07 \mathrm{a}^{\mathrm{Z}}$ & $0.02 \mathrm{a}$ & $0 \mathrm{a}$ & $2.88 \mathrm{a}$ & $1.46 \mathrm{a}$ & $1.35 \mathrm{a}$ & $0 \mathrm{a}$ \\
\hline Linoleic acid (5 mM) & $0.16 \mathrm{ab}$ & $0.03 \mathrm{a}$ & $0.03 \mathrm{a}$ & $5.77 \mathrm{a}$ & $5.12 \mathrm{a}$ & $1.30 \mathrm{a}$ & $0.46 \mathrm{a}$ \\
\hline Linolenic acid (5 mM) & $0.34 \mathrm{~b}$ & $0 \mathrm{a}$ & $0.25 \mathrm{~b}$ & $24.15 b$ & $14.74 \mathrm{~b}$ & $1.10 \mathrm{a}$ & $0.03 \mathrm{a}$ \\
\hline
\end{tabular}

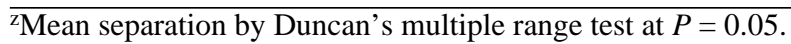


ments, control disks that had been vacuum-infiltrated with only distilled water and Tween 20 in fatty acid studies had higher levels of acetaldehyde, methanol, and ethanol than noninfiltrated controls from heat-stress experiments (Table 1, Fig. 1). Ethylene evolution rates were similar in the two experiments. Vacuum infiltration may have injured the tissues, or differences in volatile production may be partially due to unequal evolution rates over time in experiments with different sampling intervals ( 3 and $22 \mathrm{~h}$ ). Substantially larger amounts of ethane and acetaldehyde were produced after infiltration with linolenic acid compared with heat-stressed tissues.

Buffer infiltration. Methanol production increased with increasing $\mathrm{pH}$ of the infiltration solutions from 5.5 to 9.5 (Fig. 2). A linear relationship was also observed between methanol evolution and buffer concentration from 1 to $100 \mathrm{~mm}$ (Table 2). Mannitol had no significant effect on methanol evolution at the concentrations used. Low concentrations of $\mathrm{NaCl}$ seemed to repress methanol production compared to the distilled water control. Only the BTP treatment stimulated methanol evolution. Therefore, methanol production rates were probably not increased by $\mathrm{Na}$ or $\mathrm{Cl}$ ions added (as $\mathrm{NaOH}$ and $\mathrm{HCl}$ ) to adjust the $\mathrm{pH}$ of the buffers.

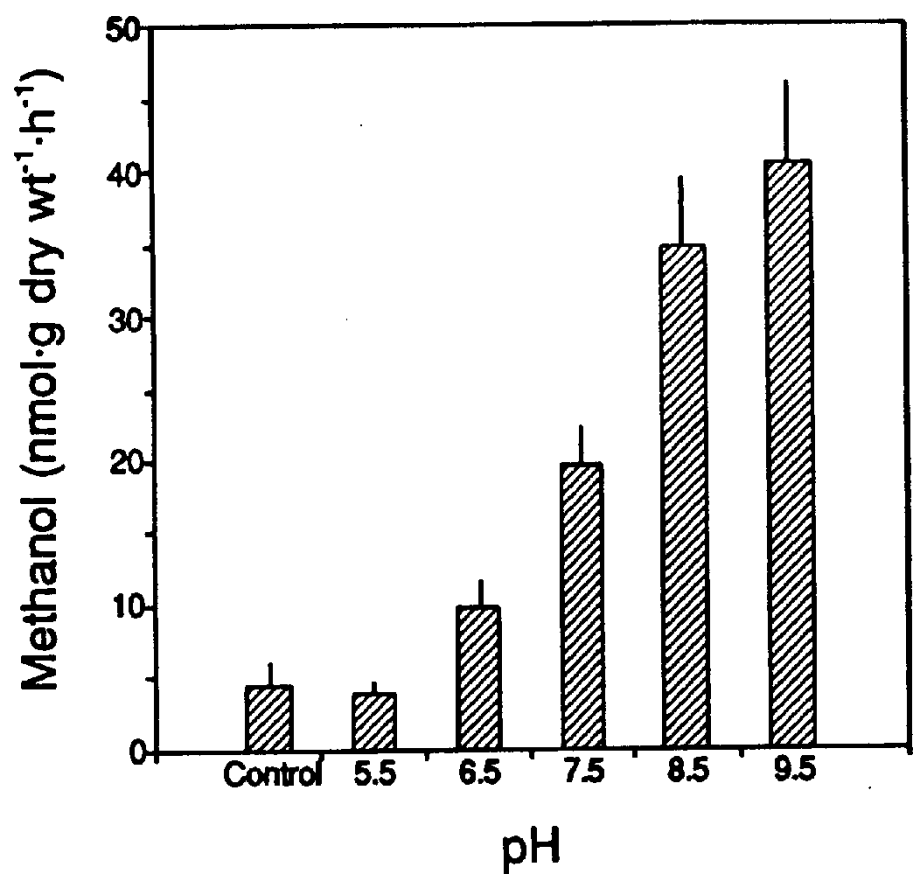

Fig. 2. Methanol production from pepper leaf disks infiltrated with distilled water (control) or $100 \mathrm{~mm}$ buffer solutions. MES = 2-[N-morpholino $]$ ethanesulfonic acid, $\mathrm{BTP}=$ bis-tris propane. Values are means \pm SE of nine measurements.

Table 2. Effect of $\mathrm{NaCl}$, mannitol, or bis-tris propane $(\mathrm{BTP})(\mathrm{pH}=9.5)$ on methanol production from pepper leaves. Controls infiltrated with distilled water produced $4.4 \pm 0.2$ (mean $\pm \mathrm{SE}) \mathrm{nmol}$ methanol/g dry wt per $h$. Values are means of nine measurements.

\begin{tabular}{lccr}
\hline \multirow{2}{*}{ Concn $(\mathrm{mM})$} & \multicolumn{3}{c}{ Methanol production $(\mathrm{nmol} / \mathrm{g}$ dry wt per $\mathrm{h})$} \\
\cline { 2 - 4 } & $\mathrm{NaCl}$ & Mannitol & \multicolumn{1}{c}{ BTP } \\
\hline 1 & $1.2 \pm 0.4$ & $3.4 \pm 0.5$ & $2.9 \pm 0.7$ \\
100 & $2.3 \pm 0.4$ & $3.2 \pm 0.5$ & $27.2 \pm 2.9$ \\
Significance & $5.1 \pm 0.3$ & $3.1 \pm 0.6$ & $41.9 \pm 5.9$ \\
$\quad$ Linear & $* *$ & & $*$ \\
Quadratic & $\mathrm{NS}$ & $\mathrm{NS}$ & $\mathrm{NS}$ \\
\hline Ns,***Nonsignificant or significant at $P=0.01$, respectively. &
\end{tabular}

$\mathrm{Ns}^{* * *}$ Nonsignificant or significant at $P=0.01$, respectively.
The difference in methanol production from heat-stressed pepper and corn leaves (Fig. 1) is consistent with the greater level of pectins in dicots compared with monocots (Brett and Waldron, 1990). Preliminary studies, using a technique developed by Maness and coworkers (1990) to measure the degree of methylation of galacturonic acid residues in cell walls, support methanol being derived from cell wall pectins. A reduction in methylation from $40 \%$ to $10 \%$ was observed in heat-stressed pepper leaf tissues compared with controls (unpublished data). Stimulated methanol production from pepper leaves at higher $\mathrm{pH}$ (Fig. 2) may have been due to either increased pectin methylesterase activity or to nonenzymatic base hydrolysis of methyl esters in pectic compounds in the cell wall. McFeeters and Armstrong (1984) measured methanol evolution from isolated cell walls treated with $\mathrm{NaOH}$. Pectin methylesterase activity in cucumbers (Fukushima, 1978) and tomatoes (Lycopersicon esculentum Mill.) (Voragen, 1972) exhibited a $\mathrm{pH}$ optimum at 7 to 7.5 . If methanol was enzymatically derived from cell wall pectins in the present study, pectin methylesterase activity in pepper leaves exhibited a $\mathrm{pH}$ optimum higher than cucumbers and tomatoes. It is possible that heat-stressinduced changes in membrane permeability increased the $\mathrm{pH}$ of the cell wall solution and stimulated methanol production.

\section{Literature Cited}

Adams, D.O. and S.F. Yang. 1979. Methionine metabolism in apple tissues. Plant Physiol. 60:892-896.

Anderson, J., G. McCollum, and W. Roberts. 1990. High temperature acclimation in pepper leaves. HortScience 25:1272-1274.

Brett, C. and K. Waldron. 1990. Physiology and biochemistry of plant cell walls. Unwin Hyman, London.

Chalker-Scott, L., L.H. Fuchigami, and R.M. Harber. 1989. Spectrophotometric measurement of leached phenolic compounds as an indicator of freeze damage. J. Amer. Soc. Hort. Sci. 114:315-319.

Dumelin, E.E. and A.L. Tappel. 1977. Hydrocarbon gases produced during in vitro peroxidation of polyunsaturated fatty acids and decomposition of preformed hydroperoxides. Lipids 12:894-900.

Elstner, E.F. and J.R. Konze. 1976. Effect of point freezing on ethylene and ethane production by sugar beet leaf disks. Nature 263:351-352.

Fukushima, T. 1978. Chilling-injury in cucumber fruits. VI. The mechanism of pectin de-methylation. Scientia Hort. 9:215-226.

Gur, A., B. Bravdo, and Y. Mizrahi. 1972. Physiological responses of apple trees to supraoptimal root temperature. Physiol. Plant. 27:130 138.

Harber, R.M. and L.H. Fuchigami. 1986. The relationship of ethylene and ethane production to tissue damage in frozen rhododendron leaf disks. J. Amer. Soc. Hort. Sci. 111:434-436.

John, W.W. and R.W. Curtis. 1977. Isolation and identification of the precursor of ethane in Phaseolus vulgaris L. Plant Physiol. 59:521-522.

Kimmerer, T.W. and R.C. MacDonald. 1987. Acetaldehyde and ethanol biosynthesis in leaves of plants. Plant Physiol. 84:1204-1209.

Kimmerer, T.W. and T.T. Kozlowski. 1982. Ethylene, ethane, acetaldehyde, and ethanol production by plants under stress. Plant Physiol. 69:840-847.

Little, T.M. and F.J. Hills. 1978. Agricultural experimentation, design and analysis. Wiley, New York.

MacDonald, R.C. and R. Fall. 1992. Methanol emission from plants. Plant Physiol. 99(Suppl.) 1:72 (Abstr.).

Maness, N.O., J.D. Ryan, and A.J. Mort. 1990. Determination of the degree of methyl esterification of pectins in small samples by selective reduction of esterified galacturonic acid to galactose. Anal. Biochem. 185:346-352.

McFeeters, R.F. and S.A. Armstrong. 1984. Measurement of pectin methylation in plant cell walls. Anal. Biochem. 139:212-217.

Nanaiah, G.K. and J.A. Anderson. 1992. Electrolyte leakage and evolution of ethylene and ethane from pepper leaf disks following temperature stress and fatty acid infiltration. J. Amer. Soc. Hort. Sci. 117:846-851. 
Perata, P. and A. Alpi. 1991. Ethanol-induced injuries to carrot cells. Plant Physiol. 95:748-752.

Robinson, T. 1991. The organic constituents of higher plants. 6th ed. Cordus, North Amherst, Mass.

Saltveit, Jr., M.E. and W.E. Ballinger. 1983. Effects of anaerobic nitrogen and carbon dioxide atmospheres on ethanol production and postharvest quality of 'Carlos' grapes. J. Amer. Soc. Hort. Sci. 108:462-465.

Smagula, J.M. and W.J. Bramlage. 1977. Acetaldehyde accumulation: Is it a cause of physiological deterioration of fruits? HortScience 12:200
203.

Voragen, A.G.J. 1972. Characterization of pectin lyases on pectins and methyl oligogalacturonates. Centre Agr. Publ. and Documentation. Wageningen Agr. Res. Rpt. 780.

Wise, R.R. and A.W. Naylor. 1987. Chilling-enhanced photooxidation. Plant Physiol. 83:272-277.

Woodstock, L.W. and R.B. Taylorson. 1981. Ethanol and acetaldehyde in imbibing soybean seeds in relation to deterioration. Plant Physiol. 67:424-428. 